\title{
Convenient Synthesis of Thiolactones and Episulfides
}

\author{
Takeshi Toru* and Toshiya Kanefusa \\ Department of Applied Chemistry, Nagoya Institute of Technology, \\ Gokiso, Showa-ku, Nagoya 466, Japan
}

\begin{abstract}
Se-Phenyl (selenothioperoxy)alkynoates give phenylselenoalkylidene butyrothiolactones on heating with AIBN. Treatment of Se-phenyl cycloalkene(selenothioperoxy)carboxylates with NBS affords bromothiolactones which can be converted to episulfides.
\end{abstract}

Previously we reported a convenient synthesis of Se-phenyl (selenothioperoxy)carboxylates from carboxylic acids (1). We have demonstrated that Se-phenyl (selenothioperoxy)carboxylates are useful synthetic precursors for introducing both a thioester and a phenylseleno group into a molecule: Se-phenyl (selenothioperoxy)benzoate, on heating in the presence of azobisisobutyronitrile (AIBN) or irradiation, undergoes intermolecular selenothiocarboxylation of olefins to give addition products (2). Se-Phenyl (selenothioperoxy)carboxylates bearing a double bond give seleno-substituted thiolactones (3). We here disclose a selenothiolactonization of Se-phenyl (selenothioperoxy)alkynoates and a bromothiolactonization of Se-phenyl cycloalkene(selenothioperoxy)carboxylates, the latter of which is followed by an efficient transformation into episulfides.

Se-Phenyl (selenothioperoxy)alkynoates 1. can be prepared according to the procedure we reported (1): For example, heptynoic acid was converted to the acid chloride which was then treated with sodium hydrosulfide in $80 \%$ aqueous ethanol at $0{ }^{\circ} \mathrm{C}$. Thioheptynoic acid obtained was then treated with $\mathrm{N}$-phenylselenophthalimide in dichloromethane at $-78{ }^{\circ} \mathrm{C}$ to give Se-phenyl (selenothioperoxy)heptynoate $\underline{1 \mathrm{a}}$ in $89 \%$ yield based on the acid. A benzene solution of (selenothioperoxy)carboxylate $\underline{\mathbf{1 a}}$ was then heated under reflux in the presence of AIBN (10 mol\%) for $11 \mathrm{~h}$ to give $(E)$ - and $(Z)$-selenothiolactones $(E)-2$ a $(4)$ and $(Z)$ 2a (5) in 78 and $13 \%$ yields, respectively. Reaction of $\mathbf{1 b}\left(\mathrm{R}=\mathrm{CH}_{3}\right)$ and $\mathbf{1 c}(\mathrm{R}=\mathrm{H})$ also resulted in the predominant formation of E-isomers as shown in Table 1. 
Table 1. Selenothiolactonization of Se-Phenyl (Selenothioperoxy)alkynoates $\underline{1}$

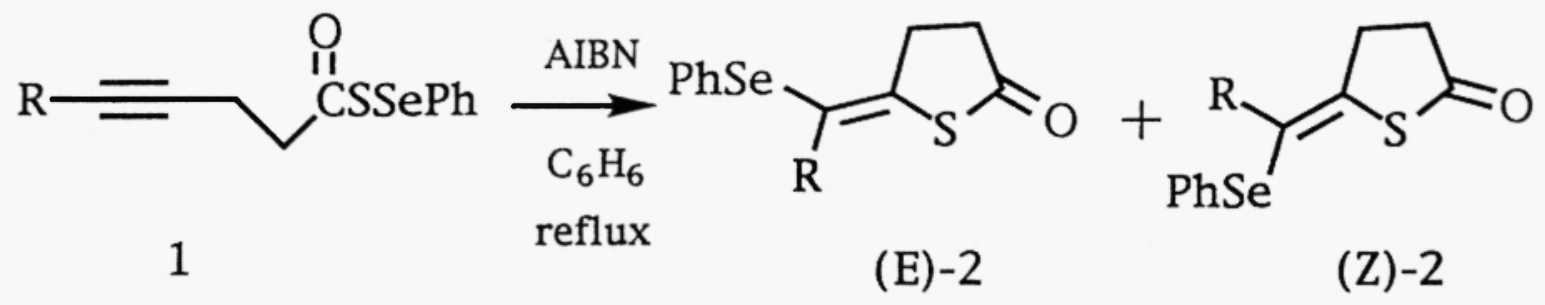

\begin{tabular}{|c|c|c|c|c|}
\hline \multicolumn{2}{|c|}{ substrate } & \multirow{3}{*}{$\begin{array}{l}\begin{array}{l}\text { reaction } \\
\text { time, } \mathrm{h}\end{array} \\
11\end{array}$} & \multirow{2}{*}{\multicolumn{2}{|c|}{$\underset{(\mathrm{E})-2}{\text { products, yields, }} \%$}} \\
\hline no. & $\mathrm{R}$ & & & \\
\hline $1 a$ & $\mathrm{C}_{2} \mathrm{H}_{5}$ & & 78 & 13 \\
\hline $1 b$ & $\mathrm{CH}_{3}$ & 6 & 78 & 14 \\
\hline $1 c$ & $\mathrm{H}$ & 4 & 59 & 18 \\
\hline
\end{tabular}

These reactions are likely to proceed via a thiyl radical intermediate as in the addition reaction of Se-phenyl (selenothioperoxy)benzoate to 1-decene-which was shown to be inhibited in the presence of hydroquinone as a radical scavenger (2). The results are in good accord with those in the exo-digonal (6) radical-mediated cyclization reported which generally give a mixture of $\mathrm{E}$ - and $\mathrm{Z}$-isomers, the $\mathrm{E}$ isomer being predominant (7).

(Selenothioperoxy)carboxylates are susceptible not only to radical species as shown above but also to the ionic reaction, namely they react with amines as acylating reagents to give acylated amines (8). We examined the reaction of cycloalkene(selenothioperoxy)carboxylates with NBS. Thus, a dichloromethane solution of (selenothioperoxy)carboxylate $\underline{\mathbf{5 a}}$ was treated with 1.0 equivalent of $\mathrm{NBS}$ at $-78{ }^{\circ} \mathrm{C}$, giving the bromothiolactone $\mathbf{6 a}(9)$ in $97 \%$ yield. (Selenothioperoxy)carboxylates $\underline{\mathbf{5 b}}$ and $\underline{5 c}$ gave the corresponding bromothiolactones $\underline{6 b}$ and $\underline{6 c}$ in moderate yields (Scheme 1). This bromothiolactonization probably proceeds via ionic intermediates not via a radical pathway, although the precise reaction mechanism is not clear at this moment. It is noteworthy that (selenothioperoxy)carboxylates were superior substrates for bromothiolactonization, since treatment of thiocarboxylic acids $\mathbf{7} \mathbf{a}$ and $\mathbf{7 b}$ with NBS forms bromothiolactones in much lower yield (Scheme 2). 

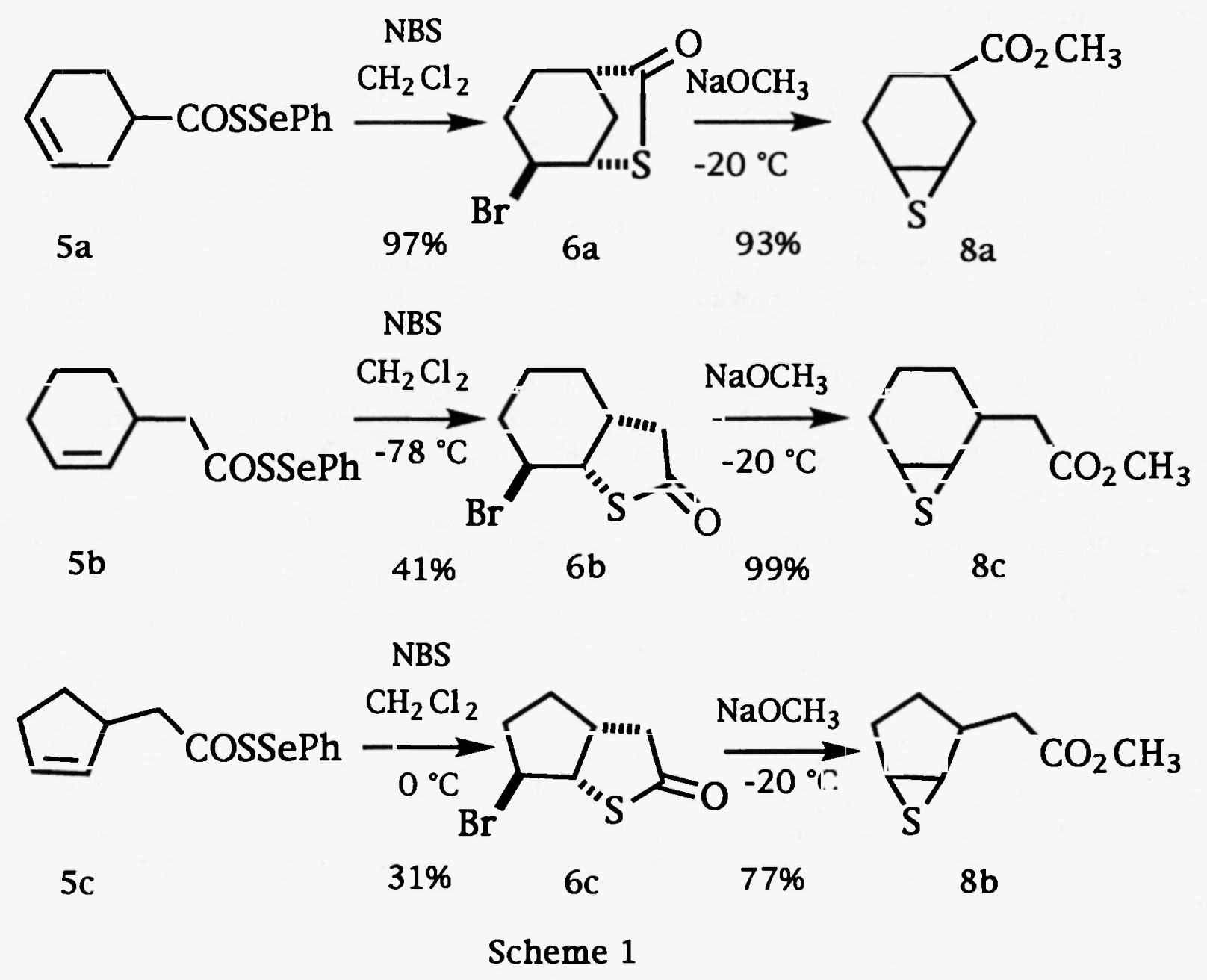

Bromothiolactones could be transformed to episulfides. Thus, treatment of the bromothiolactone oa with 1.0 equivalent of sodium methoxide in methanol at $-20{ }^{\circ} \mathrm{C}$ gave the episulfide $\mathbf{8 a}$ in $93 \%$ yield. The other two bromothiolactones $\underline{\mathbf{6 b}}$ and $\mathbf{6 c}$ also afforded the episulfides in high yields (Scheme 1).

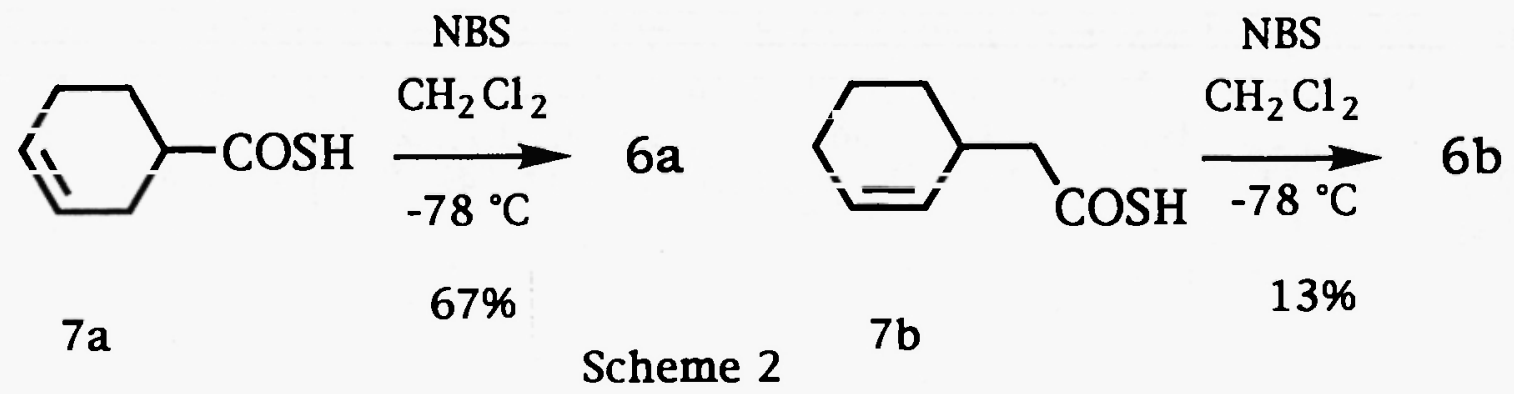




\section{References and notes}

(1) T. Toru, M. Nishigaki, T. Seko, T. Kanefusa and E. Maekawa, Synthesis, 879 (1985)

(2) T. Toru, T. Seko and E. Maekawa, Tetrahedron Lett., 26, 3263 (1985); T. Toru, T. Seko, E. Maekawa and Y. Ueno, J. Chem. Soc. Perkin Trans. 1, 575 (1988); T. Toru, Y. Yamada, E. Maekawa and Y. Ueno, Bull. Chem. Soc., Jpn., 61, 2205 (1988); T. Toru, T. Seko, E. Maekawa and Y. Ueno, J. Chem. Soc., Perkin Trans. 1, 1927 (1989)

(3) T. Toru, T. Kanefusa and E. Maekawa, Tetrahedron Lett., 27, 1583 (1986); T. Toru, T. Kanefusa, E. Maekawa, Y. Ueno, K. Kondo and S. Eguchi, Bull. Chem. Soc. Jpn., 61, 2675 (1988); T. Toru, Y. Yamada, E. Maekawa and Y. Ueno, Chem. Lett., 1827 (1987)

(4) (E)-2. IR $1706 \mathrm{~cm}-1 ;{ }_{1} \mathrm{H}$ NMR $\left(\mathrm{CDCl}_{3}\right) \delta 1.08(3 \mathrm{H}, \mathrm{t}, \mathrm{J}=7.60 \mathrm{~Hz}), 2.34(2 \mathrm{H}$, qd, $\mathrm{J}=7.64,0.52 \mathrm{~Hz}), 2.78(1 \mathrm{H}, \mathrm{dd}, \mathrm{J}=8.75,0.75 \mathrm{~Hz}), 2.81(1 \mathrm{H}, \mathrm{dd}, \mathrm{J}=8.0,0.75 \mathrm{~Hz})$, $3.10(1 \mathrm{H}, \mathrm{ddt}, \mathrm{J}=8.75,0.75,0.52 \mathrm{~Hz}), 3.14(1 \mathrm{H}$, ddt, J=8.0, 0.75, $0.52 \mathrm{~Hz}), 7.22$ $7.38(3 \mathrm{H}, \mathrm{m}), 7.38-7.54(2 \mathrm{H}, \mathrm{m})$; ${ }^{13} \mathrm{C}$ NMR $\left(\mathrm{CDCl}_{3}\right) 12.7,32.1,32.9,41.8,125.8$, $127.0,129.3,130.5,131.5,138.8,209.5$.

(5) (Z)-2. IR $1707 \mathrm{~cm}^{-1} ;{ }^{1} \mathrm{H} \mathrm{NMR}\left(\mathrm{CDCl}_{3}\right) \delta 1.06(3 \mathrm{H}, \mathrm{t}, \mathrm{J}=7.5 \mathrm{~Hz}), 2.40(2 \mathrm{H}, \mathrm{q}, \mathrm{J}=7.5$ $\mathrm{Hz}), 2.88(1 \mathrm{H}, \mathrm{dd}, \mathrm{J}=6.7,3.8), 2.92(1 \mathrm{H}, \mathrm{dd}, \mathrm{J}=6.0,1.2 \mathrm{~Hz}), 3.01(1 \mathrm{H}$, ddt, J=6.7, $1.2,0.05 \mathrm{~Hz}), 3.05(1 \mathrm{H}$, ddt, J=6.0, 3.8, $0.05 \mathrm{~Hz}), 7.15-7.39(3 \mathrm{H}, \mathrm{m}), 7.39-7.52$ $(2 \mathrm{H}, \mathrm{m}) ;{ }^{13} \mathrm{C}$ NMR $\left(\mathrm{CDCl}_{3}\right) 13.6,28.3,28.8,42.8,127.3,129.3,130.1,132.2$, $138.1,177.7$.

(6) J. E. Baldwin, J. Chem. Soc., Chem. Commun., 734 (1976)

(7) For example, W. B. Motherwell and D. Crich, "Free Radical Reactions in Organic Synthesis"; Academic Press, New York, 1992, Chapter 7; B. Giese, "Radicals in Organic Synthesis: Formation of Carbon-Carbon Bonds"; Pergamon Press, Oxford, 1986, Chapters 2 and 4.

(8) T. Toru, Y. Yamada, T. Oshima, S. Imao, and E. Maekawa, Nippon Kagaku Kaishi, 1443 (1987)

(9) 6a. IR $1700 \mathrm{~cm}^{-1} ; 1 \mathrm{H}$ NMR $1.79(1 \mathrm{H}$, dddd, J=12.1, 8.4, 4.2, $1.3 \mathrm{~Hz}), 1.93(1 \mathrm{H}$, dddd, J=13.7, 5.0, 4.2, $2.8 \mathrm{~Hz}), 2.01(1 \mathrm{H}$, ddd, J=13.7, 8.4, $5.7 \mathrm{~Hz}), 2.32(1 \mathrm{H}$, ddd, J=12.5, 4.3, 5.6 Hz), $2.64(1 \mathrm{H}$, ddd, J=5.7, 2.8, 4.3 Hz), $2.80(1 \mathrm{H}, \mathrm{d}, \mathrm{J}=12.5$ $\mathrm{Hz}), 2.83(1 \mathrm{H}$, ddd, J=12.1, 4.3, $5.0 \mathrm{~Hz}), 4.12(1 \mathrm{H}, \mathrm{dd}, \mathrm{J}=4.3,5.6 \mathrm{~Hz}), 4.59(1 \mathrm{H}$, ddd, $\mathrm{J}=4.3,4.3,1.3 \mathrm{~Hz}$ ). 